\title{
Application of Inquiry Teaching Methods in Primary School Mathematics Curriculum
}

\author{
Ying Dai \\ School of Education and Sports, Bohai University, Jinzhou, 121013, China \\ bhdxdy@126.com
}

Keywords: inquiry teaching; teaching methods; primary school mathematics; application strategies

\begin{abstract}
The purpose of mathematics education is to cultivate students 'mathematical thinking ability, to realize the application value of mathematics and to promote students' all-round development. The introduction of inquiry teaching in the primary school stage can help students to establish awareness of inquiry and develop students' ability to analyze problems and solve problems. Based on the characteristics of primary school mathematics teaching, this paper puts forward the application strategy of inquiry teaching method in elementary school mathematics curriculum: to stimulate students' learning, and to explore the teaching method of inquiry teaching. Mathematical interest, select the appropriate inquiry-based teaching content, develop students' mathematical thinking, establish a scientific evaluation mechanism.
\end{abstract}

\section{Introduction}

Inquiry teaching is the students in the study of concepts and principles, the teacher is only given some examples and problems, so that students themselves through reading, observation, experiment, thinking, discussion and listening and other ways to independent inquiry, self-discovery and master the corresponding principle And conclusions. The guiding ideology is under the guidance of teachers, students as the main body, so that students consciously and actively explore, master the understanding and problem-solving methods and steps to study the properties of objective things, find the cause of things and things within the link, From which to find the law, the formation of their own concepts..

Exploratory teaching is an effective way for students to acquire mathematical knowledge and cultivate inquiry ability. It is not to tell students about the mathematical conclusion, but to let students through their various research activities, including observation, experiment, investigation, collection of information, conjecture and argument, etc. Draw a mathematical conclusion. The process of discovery, exploration and research in mathematics learning process highlights the students to participate in and experience the acquisition of mathematical knowledge process, the construction of a new understanding of mathematics, training mathematics inquiry ability. Through the mathematical inquiry teaching, students can understand the mathematical knowledge from multiple angles and in depth, which is helpful to construct the connection between mathematics knowledge, so that students can more easily activate the mathematics knowledge when faced with practical problems and use mathematics knowledge to solve the problem.

In primary school teaching, not only to teach students the knowledge of mathematical theory, but also to enable students to learn to use theoretical knowledge, the knowledge applied to daily life, reflecting the students' math ability. Based on the exploratory teaching method, it can effectively cultivate the mathematics thought of primary school students and promote the improvement of mathematics literacy. In the process of exploration, let the students feel the fun of mathematics discovery, enhance the confidence of mathematics, know the mathematical knowledge, mathematical ability and mathematical thinking on the important role of daily life, know the logic of mathematics, rigorous beauty, full of love and love Awe. 


\section{Theoretical Basis of Inquiry Teaching}

Exploratory teaching is based on the following theoretical basis:

(1) Constructivist learning theory. Knowledge can not be taught by teachers and can only be constructed for learners. Mathematics learning is not a passive acceptance process, but an active construction process. From the guidance of constructivism to math learning, math knowledge can not be moved from one person to another. A person's mathematical knowledge is based on the operation and communication of the individual's experience, and is constructed by introspection. It is the individual's relatively independent creativity activity.

(2) Recent development zone theory. There are two levels of student development: one is the current level of the student, the level of problem-solving that can be achieved when the activity is independent, and the other is the potential level of development of the student through the teaching. The difference between the two is the recent development area. Teaching should focus on the student's recent development area, provide students with difficult content, mobilize the enthusiasm of students, to play its potential, beyond its recent development area to reach the next stage of development.

(3) Lifelong education theory. Lifelong education is the whole process of education from the beginning of human life to the end of human life. Life - long education criticizes the traditional school education from the concrete reality, ignoring the development of personality. Lifelong education does not take knowledge as the main goal, but to focus on personal development, recognition of the educated in the education of the dominant position, the main motivation for education is the individual education, emphasizing the purpose of education is to develop student personality and help students learn to learn.

\section{Process of Inquiry Teaching}

Exploratory teaching is an open and dynamic system. Depending on the learning content, the student's characteristics, the individual advantages of the teachers, and the resources of the teaching equipment, there are different teaching designs, but usually include five processes, as shown in the Fig.1.

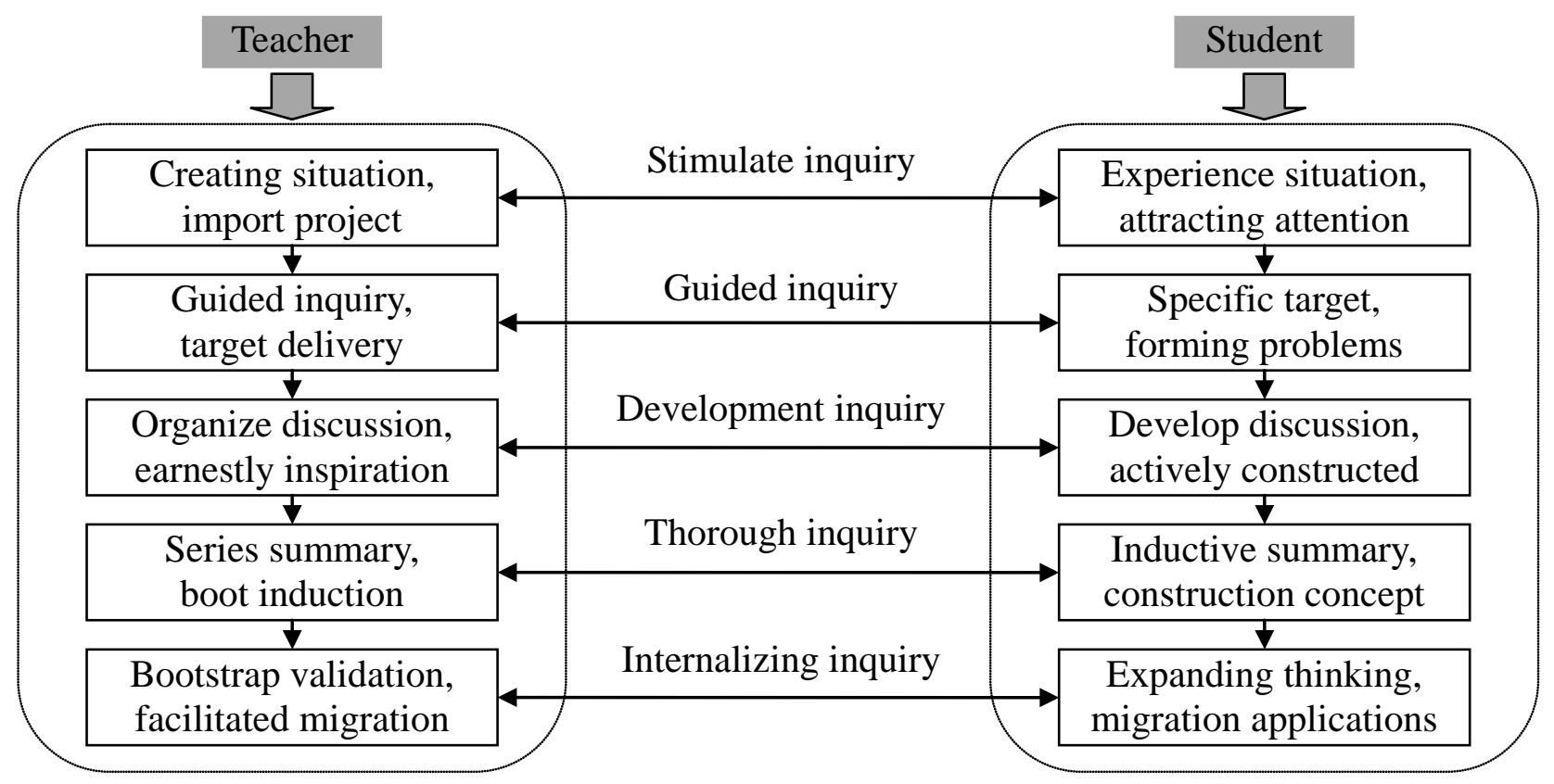

Fig. 1. Inquiry teaching process

(1) Stimulate the inquiry. Exploratory teaching of the carrier and the core is the problem, learning activities are carried out around the problem. The starting point of inquiry teaching is to set 
the question that needs to be answered, which is the starting point for further inquiry. From the teaching point of view, teachers need to be based on the purpose and content of teaching, careful consideration, put forward the difficulty of moderate and logical and reasonable problems, to stimulate students to explore the enthusiasm.

(2) Guide the study. In the new teaching philosophy, good at throwing the problem to students, to stimulate students to explore the strong desire for knowledge and innovation. Classroom teaching straight into the theme, driven by the problem. The whole teaching process follows the student's thinking process, guides the students to discover the problem and solve the problem, through the multi-angle thinking, makes the students really understand and master.

(3) Development of inquiry. Students in the relatively independent of the inquiry, will encounter some difficulties with their own ability to solve difficulties, or due to the impact of the original knowledge and experience, only pay attention to the surface of knowledge or shallow meaning. Teachers in the process of student inquiry, we must seize the opportunity to focus on the key and difficult issues necessary to dial and explain, and guide the real understanding of the essence of the problem.

(4) In-depth study. Teachers should be based on teaching content, student situation and the temporary changes in the classroom flexible use, broaden the horizons for students to leave a broader space for exploration. Through in-depth inquiry, students 'understanding of knowledge is more comprehensive and profound, the idea is more clearly organized, the information is also more abundant, and the students' self-confidence and courage are cultivated.

(5) Internalization. Knowledge internalization is the external new knowledge, through a series of intellectual activities, reorganization into individual knowledge, through the cognitive structure, assimilation and adaptation and meta-cognition and other psychological mechanisms interact. Play the overall effect of the knowledge system, promote learning and easy to remember, improve the cognitive structure of students, and lay the foundation for follow-up study.

\section{Principles of Inquiry Teaching}

Exploratory teaching should follow the following principles:

(1) The principle of autonomy. The main body of inquiry teaching is students, teaching activities to give students full time and space to think, so that students are happy to publish independent research ideas and insights, to guide students to think deeply, the opportunity to leave the students, so that students get direct Experience, to maintain lasting interest and enthusiasm, the knowledge and skills into the quality of their own students.

(2) The principle of emotion. Through the emotional induction, to mobilize the students' emotional factors, is to optimize the status of students as an important guarantee. Exploratory teaching, it is necessary to pay attention to the transmission of knowledge and information feedback, but also pay attention to the emotional integration of teachers and students. The emotional education and cognitive education organically combine, so that students in the inquiry learning to experience the fun of success.

(3) The principle of feedback. In order to ensure the correct goal of teaching, we must communicate teaching and learning, learning and learning, as well as their own reflection and other multi-directional feedback loop. The student's output information is provided directly to the teacher for feedback, used to improve the teaching, called "learning to teach feedback." Teachers according to the student's output information, "learning" to make the appropriate evaluation, known as "teaching to learn feedback."

(4) The principle of innovation. Change the teaching to the main, the book-based knowledge of the situation, highlighting the development of students-oriented modern education ideas, multi-angle to guide students to actively participate in teaching activities. Not only reflected in the form of inquiry-based teaching innovation, content innovation, but also reflected in the promotion of students' all-round development and training to become innovative talents.

(5) The principle of democracy. In inquiry classroom teaching, the relationship between teachers and students is democratic, harmonious, teachers are also learning participants, with students to 
explore and discover. Promote democracy, create a pleasant teaching atmosphere, the establishment of democratic and equal teacher-student relationship, to encourage students to question teachers, to the book questioned, not superstitious authority, bold exploration.

\section{Characteristics of Primary School Mathematics Teaching}

Mathematics is a scientific and logical a strong discipline, has a strict system and abstract, most of the knowledge points have pre-foundation, the late deepening and development. With the development of mathematics itself, it has been widely recognized that mathematics is a tool, a language, a culture. Mathematics is to promote people's ability to think of the propeller, and people's lives are inseparable. Primary school mathematics is the prerequisite for learning mathematics, physics and chemistry in middle school, and the basis for future knowledge of scientific and cultural knowledge. Primary school mathematics teaching is the teaching of thinking activities, the core is to cultivate students to master the basic knowledge of mathematics, the development of logic and innovative thinking ability, to cultivate people's innovative spirit and innovation ability as the basic value orientation. Primary school mathematics teaching has the following characteristics:

(1) Target presetting. Teaching is purposeful, planned and organized interaction between teachers and students. The default teaching goal is to refer to the purpose of education, curriculum objectives and teaching materials under the specific content of the whole classroom teaching is the starting point. The presuppositions are not rigid and fixed, but open and dynamic, leaving time and space for students to take the initiative to participate in the teaching process to continue to adjust.

(2) Content of life. The new curriculum standard pointed out that in the primary school mathematics teaching process, teachers should strengthen the mathematical knowledge and real life links, in order to promote the practical ability of students to improve. Many of the mathematical knowledge comes from life, the ultimate goal of mathematics teaching is to enable students to apply mathematical knowledge to real life, the use of mathematical knowledge to solve practical problems, improve students to analyze problems and solve practical problems.

(3) To explore cooperation. Cooperative communication is an important way for students to learn mathematics. In the atmosphere of cooperation, sharing and independent thinking, listening, questioning, persuading and promoting them is a new realm of mathematics learning. Students in their hands-on and brain-thinking process, to build their own cognitive structure, and in the process of communication, mutual inspiration, complement each other, to stimulate innovation potential.

(4) Thinking personalized. Personalized thinking is an integral part of students 'comprehensive literacy, and cultivating students' individualized thinking is an important task of mathematics teaching. In the teaching process, we should give full play to the main role of students, so that students have the space to explore their own, cultivate good math learning emotions, pay attention to mathematical thinking ability, encourage students to think, promote the formation of individual thinking, development and promotion.

\section{Application Strategies of Inquiry Teaching Methods in Primary School Mathematics Curriculum}

Through the implementation of effective strategies to promote the inquiry teaching methods in primary school mathematics curriculum applications, specific strategies are as follows:

(1) To stimulate students to learn mathematics interest. Interest can make students' cognition in the most active and active state, so that focus and focus on learning. Mathematics learning interest is the desire to acquire mathematical knowledge and explore the tendency of mathematical problems. Mathematics learning interest is the most effective driving force for students to learn mathematics. "Interest is the best teacher", teachers must change the teaching concept, teaching students to stimulate the interest of learning mathematics, students actively learning emotions, the establishment of students learning mathematics confidence. Teachers should carefully design 
classroom teaching, choose effective teaching methods, and actively mobilize the students to learn initiative and creativity in order to enable students to "learn, will learn, willing to learn."

(2) Choose the appropriate inquiry teaching content. Not all of the teaching content is suitable for inquiry teaching, some content by the teaching conditions and basic knowledge of students and other aspects of the restrictions, it is difficult to promote. Teachers choose the teaching content, should note the following: First, the choice of content is interesting. The characteristics of primary school students are curious and active, simple mathematics knowledge teaching will make students boring. To choose to help students improve the intrinsic motivation and interest in the content, to stimulate the desire to explore; second, the choice of content to be moderate. Content is too difficult, learning will be unable to start, lost to explore the confidence. Content is too easy, students feel no challenge and a sense of accomplishment, loss of inquiry enthusiasm; third, the choice of content to be gradual. The inquiry ability of primary school students is still in the initial stage, taking full account of the progressive nature and acceptability of students' learning style transformation, and follow the simple and complex step by step principle.

(3) The development of students' mathematical thinking. Thinking is the general and indirect reflection of the human brain to the objective reality. Mathematical thinking is the form of thinking activity that mathematically considers the problem and resolves the problem. The development of math thinking ability of primary school students needs to have a long training and training process. First, the effective creation of mathematical thinking situation. Create a democratic atmosphere, keep your mind open. The creation of situational issues, the provision of thinking space; second; effective "to say" mathematical thinking ability. In the mathematics classroom teaching, the need to effectively impart knowledge to students, the development of logical thinking ability, we must pay attention to the students of mathematical language training; third, effectively "sorting out" mathematical thinking thread. Teachers help students to sort out the thinking thread, pay attention to the starting point and turning point in the process of thinking, is the focus of primary school mathematics teaching ability.

(4) The establishment of a scientific evaluation mechanism. The purpose of the evaluation is to fully understand the students' learning process, to encourage students to learn enthusiasm, and promote the comprehensive development of students. Evaluation is also a powerful means for teachers to reflect and improve teaching. The evaluation of mathematics teaching should pay attention to the students' learning results, but also pay attention to the learning process, level, emotion and attitude, to help students understand themselves, build confidence. The specific strategies include: updating the concept, grasping the essence of "promoting development"; using different scale evaluation, paying attention to the difference of students' level; focusing on the evaluation language, showing the incentive function of evaluation; real-time evaluation and delay evaluation, ; Self-evaluation and mutual evaluation of the combination, to play the evaluation of the exchange function.

\section{References}

[1] X. W. Zhang, "Application of inquiry teaching in primary school mathematics teaching," Science and Technology Innovation Herald, vol. 14, no. 3, pp. 219-220, 2017.

[2] G. S. Wang, "Research of Inquiry Based Mathematics Teaching Based on Technology," E-Education Research, vol. 33, no. 3, pp. 91-95, 2012.

[3] G. F. Liang, "Characteristics and methods of mathematics teaching in primary school," Digital Fashion, vol. 9, no. 4, pp. 83-83, 2014.

[4] B. J. Kuang, "Mathematics teaching in primary school to cultivate students' ability to solve problems," Contemporary teaching research, vol. 3, no. 11, pp. 59-59, 2014.

[5] Baidu Wenku, "Four characteristics of primary school mathematics teaching," https://wenku.baidu.com/view/b3abaac428ea81c758f57845.html, 2017-5-22. 
[6] Baidu Knows, "Characteristics of primary school mathematics teaching," https://zhidao.baidu.com/question/517287451.html, 2017-5-22.

[7] L. J. Ma, "Analysis of the application of mathematics inquiry teaching method in primary school," Education Teaching Forum, vol. 8, no. 4, pp. 281-282, 2016. 